\title{
Ascaris lumbricoides causing obscure gastrointestinal bleeding detected by double-balloon enteroscopy
}

A 79-year-old male patient was referred to hospital for investigation of microcytic hypochromic anemia. His previous medical history included coronary heart disease, cardiac insufficiency, chronic renal failure, percutaneous aortic valve replacement, and chronic atrial fibrillation with phenprocoumon as regular medication. He reported episodes of fatigue, no alteration of stools or stool color, and no other complaints. Physical examination showed unremarkable findings. Laboratory investigation showed microcytic anemia (hemoglobin $8.2 \mathrm{mg} / \mathrm{dL}$ ). Upper and lower endoscopy showed no relevant abnormalities, but a large amount of blood was evacuated from the terminal ileum. Capsule endoscopy was performed and revealed a bleeding source in the middle jejunal region and a foreign body, suspected of possibly being part of a nasogastric tube (৫ Fig. 1).

As the patient needed transfusion of erythrocyte concentrates, a double-balloon enteroscopy was performed to diagnose and stop the gastrointestinal bleeding by removing the foreign body. During endoscopy a roundworm of length $22 \mathrm{~cm}$ (৫ Fig. 2) was extracted from the jejunum at approximately $140 \mathrm{~cm}$ post pylorus. It was identified as Ascaris lumbricoides ( $\bullet$ Fig.3). Local mucosal bleeding in the area where the roundworm could suck stopped rapidly after removal of the parasite ( Fig.4). Oral mebendazol therapy for 3 days was initiated.

Ascaris lumbricoides is an intestinal roundworm, which is one of the most common helmintic human infections worldwide, especially in hot and wet climates, but it is rarely diagnosed in Western Europe [1]. Transmission usually occurs via ingestion of contaminated water or food [2]. In our patient transmission most likely occurred via a contaminated imported organic salad. Adult worms inhabit the lumen of the small intestine, usually the ileum or jejunum [3]. While the majority of infections are asymptomatic, severe symptoms may also be caused, such as bowel obstruction [4],

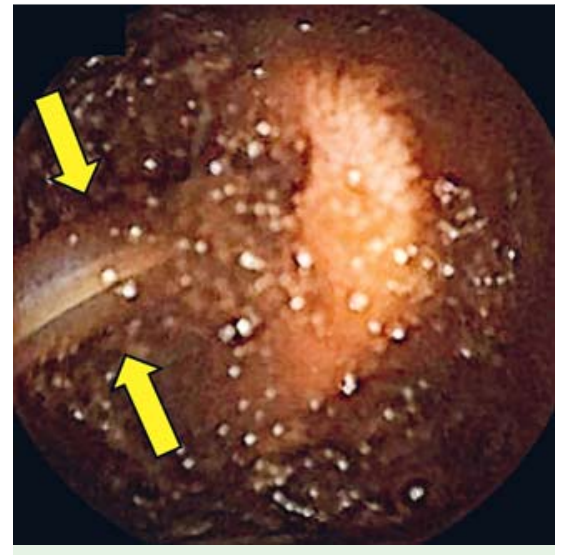

Fig. 1 During investigation of microcytic hypochromic anemia in a 79-year-old man, capsule endoscopy showed gastrointestinal bleeding, with a foreign body (arrows) in the middle to distal jejunum

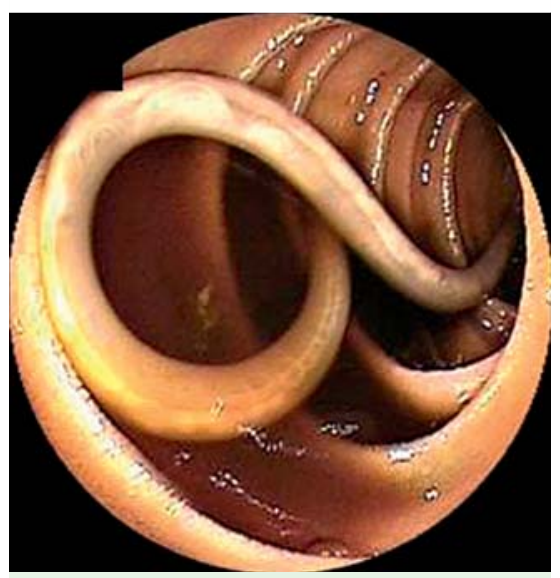

Fig. 3 Enteroscopic view of the middle jejunum, with the "foreign body" previously seen by capsule endoscopy.

pancreatitis, cholangitis, or anemia resulting from direct tissue damage. In this patient the effect of the tissue damage was aggravated by anticoagulant medication, leading to continuing gastrointestinal bleeding. In general, in symptomatic patients treatment with antihelmintic drugs is advised.

Endoscopy_UCTN_Code_CCL_1AC_2AG

Competing interests: None

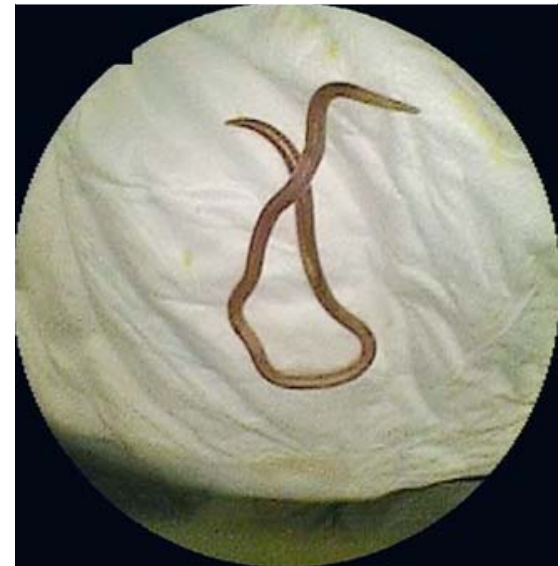

Fig. 2 Ascaris lumbricoides after endoscopic extraction from the intestine.

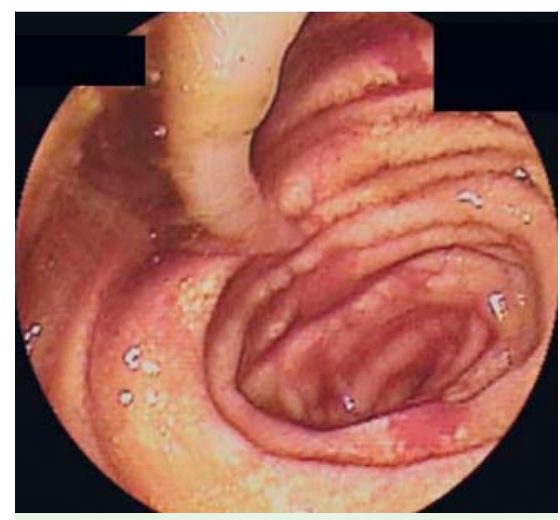

Fig. 4 Enteroscopic view of bleeding in the vicinity of the roundworm's "sucking" parts.

\section{Benjamin M. Walter ${ }^{1,2}$, Peter Born', Jürgen Winker ${ }^{1}$}

${ }^{1}$ II. Medizinische Klinik, Rotkreuzklinikum München, Munich, Germany

2 II. Medizinische Klinik und Poliklinik, Klinikum rechts der Isar der Technischen Universität München, Munich, Germany 


\section{References}

1 Bethony J, Brooker S, Albonico M et al. Soiltransmitted helminth infections: Ascaris, trichuriasis, and hookworm. Lancet 2006; 367: 1521 - 1532

2 Strunz EC, Addiss DG, Stocks ME et al. Water, sanitation, hygiene, and soil-transmitted helminth infection: a systematic review and meta-analysis. PLoS Med 2014; 11: e1001620

3 Cooper P, Chico M, Sandoval C et al. Human infection with Ascaris lumbricoides is associated with a polarized cytokine response. J Infect Dis 2000; 182: 1207-1213

4 Akgun Y. Intestinal obstruction caused by Ascaris lumbricoides. Dis Colon Rectum 1996; 39: $1159-1163$
Bibliography

Dol http://dx.doi.org/

10.1055/s-0034-1392422

Endoscopy 2015; 47: E354-E355

(c) Georg Thieme Verlag KG

Stuttgart · New York

ISSN 0013-726X
Corresponding author

Benjamin Walter, MD

Klinikum rechts der Isar der Technischen Universität München

II. Medizinische Klinik

Ismaninger Str. 22

81675 Munich

Germany

Fax: +49-89-41404905

Benjamin.walter@Irz.tum.de 